\title{
Design and Commissioning of a Community Scale Solar Powered Membrane-Based Water Purification System in Haiti
}

\author{
Shavin Pinto*, Yung Wong, Kyle Fennesy, Yan Tang, Marc Compere \\ Embry-Riddle Aeronautical University, Mechanical Engineering, Daytona Beach, FL, USA \\ Shaveen.Pinto@gmail.com
}

\begin{abstract}
This paper presents the design and commissioning of a solar powered water purification system at the Ryan Epps Home for Children (REHC) in Michaud, Haiti. This system supplies clean drinking water to the 200 children who live and go to school at REHC and also to the community in the form of a micro-business. This micro-business is the mechanism for income generation for sustainable system operation. The purifier uses a three stage filtration system with a disc-type sediment filter, a 0.1 micron ultrafiltration membrane, and an ultraviolet light for disinfection. The backwash cycle extends the life of the ultrafiltration membrane to $4-7$ years before a new filter is required. Simplicity in operation was an important design consideration because it facilitates local operator training, and understanding. To further ensure complete understanding of operation, a pictorial quick-start manual was developed so that operators only need to follow the diagrams laid out on the manual. The design folder with CAD drawings, schematics, datasheets, and troubleshooting guide are left with the local operators. Testing before shipping and after installation to ensure proper operation upon installation and on-site water quality testing ensures it will promote improved community health.
\end{abstract}

KEYWORDS: Community development, water purification, solar power, off-grid electricity, membrane filtration, WASH training

\section{INTRODUCTION}

The 7.0 magnitude earthquake that struck Haiti on January 2010 took the lives of over 200,000 people and left 1.5 million people homeless (Lies, 2011). The desperate need for basic necessities such as food and water encouraged Embry-Riddle Aeronautical University (ERAU) students to establish Project Haiti, a student led movement to improve the livelihood of Haitian communities (Tang et al., 2012). Since 2010, ERAU students have designed and installed community scale solar powered water purification systems in various Haitian communities. The initial system installed in Haiti during 2010 was able to provide just 3.8 litres per minute (L/min). Since then, the project has evolved immensely and by 2012, ERAU students designed a system capable of providing over 76,000 litres of water at $76 \mathrm{~L} / \mathrm{min}$ (Wong et al., 2014). The system was installed at Onaville, one of Haiti's largest tent cities, which has a population of about 100,000. This paper presents ERAU's 4th system that was installed at Ryan Epps Home for Children (REHC) during the summer of 2013. The purifier is capable of producing 30,000 litres of potable water powered entirely by the sun. The water source for the system is a $40 \mathrm{~m}$ (metre) deep bore well with a $0.15 \mathrm{~m}$ diameter. In addition to providing water for the general operations of the orphanage, ERAU collaborated with local Haitians to implement a micro-business to sell the excess water to surrounding communities to generate income to sustain the purifier. Water, Sanitation and Hygiene (WASH) training sessions were also performed to educate Haitian communities and to improve their general wellbeing.

\section{PROJECT OVERVIEW}

\subsection{Design Goals}

Since the system is operated and maintained by local non-technical operators, the main design goal was to accomplish a sustainable design that would require minimal maintenance and simple operational tasks.

The stages of filtration that the system utilises were chosen specifically to eliminate the need for cartridge replacement. A system that requires frequent cartridge replacement would be a burden for the Haitian operators in terms of cost. Limited availability in Haiti would also lead to the operators having to import the desired filter cartridges from overseas. For this reason, the main filtration components are capable of being backwashed or can be cleaned manually.

Since the system is designed for a community, a high flow rate is critical to distribute the potable water effectively. The main filtration mechanism of the purifier is an ultra-filtration (UF) membrane. This allows the system to provide up to 30,000 litres of water per day operating at the high flow rate of $38 \mathrm{~L} / \mathrm{min}$.

The design excluded the use of complex electronics to avoid maintenance complications in the field. To switch back and forth from filtration mode to backwash mode, the system utilises a simple valve mechanism that allows for field serviceability. Timers and time-delay relays control the filtration run-time and backwash run-time. Avoiding sensitive electronics has led to a simpler design that is easier to maintain and repair. 


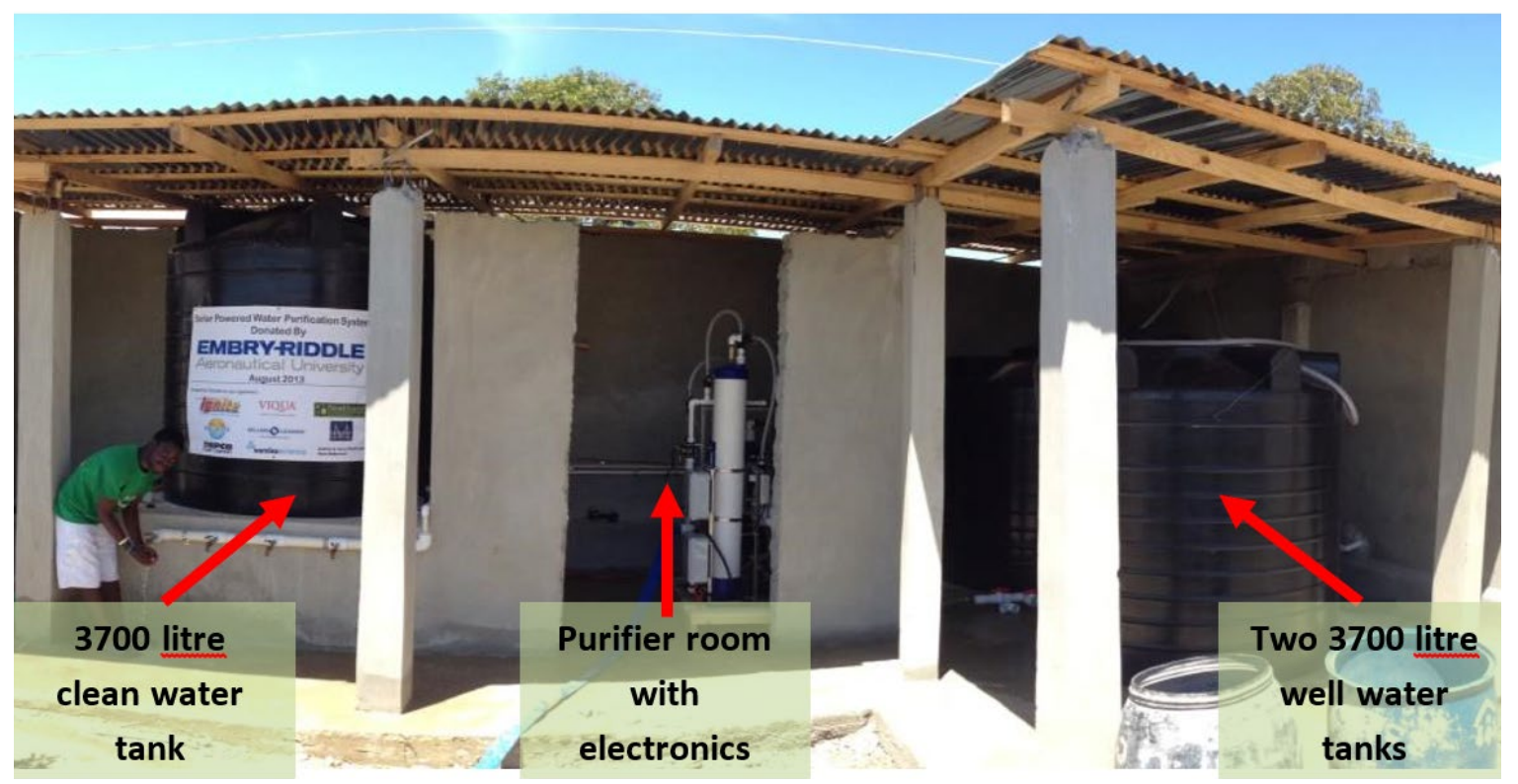

Figure 1: Purification system layout with well water tanks, purifier and clean water tank

Figure 2: Overall site layout

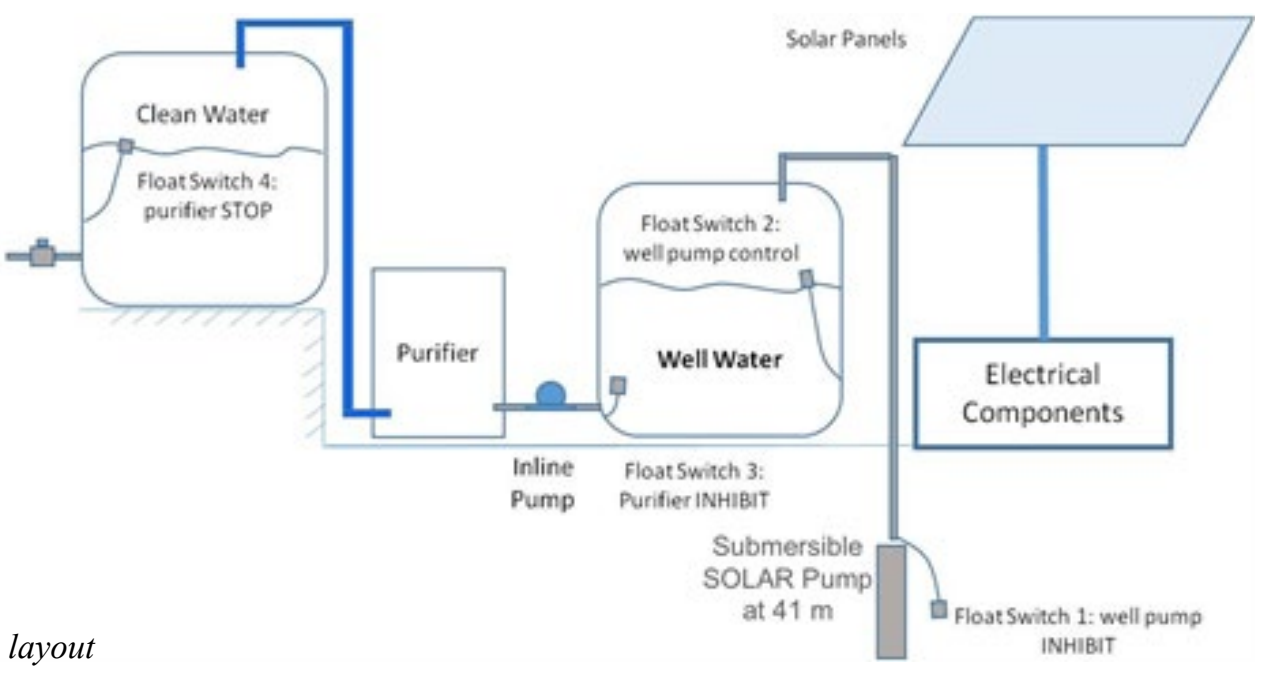

\subsection{Site Layout}

Planning of the site layout began four months before the travel date to Haiti for installation. ERAU students collaborated with representatives of REHC to ensure all requirements were met from both parties. Figure 1 illustrates the purifier system layout and Figure 2 illustrates the overall site layout.

The two 3,700 litre tanks are placed to the left of the purifier. The purifier and electronics are stored in a secure enclosure. The 3,700 litre clean-water tank is placed on a raised platform so that the purified water can be gravityfed to the distribution rail, eliminating the need for an additional pump. The solar panels were mounted on the roof of a hurricane-proof building. REHC has security guards on site at all times. Teaming with a suitable installation partner that meets the criteria facilitates the installation process and also leads to a sustainable project with proper management.

\section{PURIFIER PROCESS DESIGN}

\subsection{Stages of Filtration}

As illustrated in Figure 3, the system utilises three stages of filtration. First, the well water passes through a disc filter that removes sediment larger than 50 micron. As the water passes from the outside of the discs to the inside, grooves molded into the surface of the discs trap the sediment. These discs can be manually cleaned and be reused. A high velocity centrifugal action inside the filter housing causes the sediments to spin away from the disc cartridge to the base of the filter (Leaman, n.d.). The accumulated sediment can then be flushed from the filter 


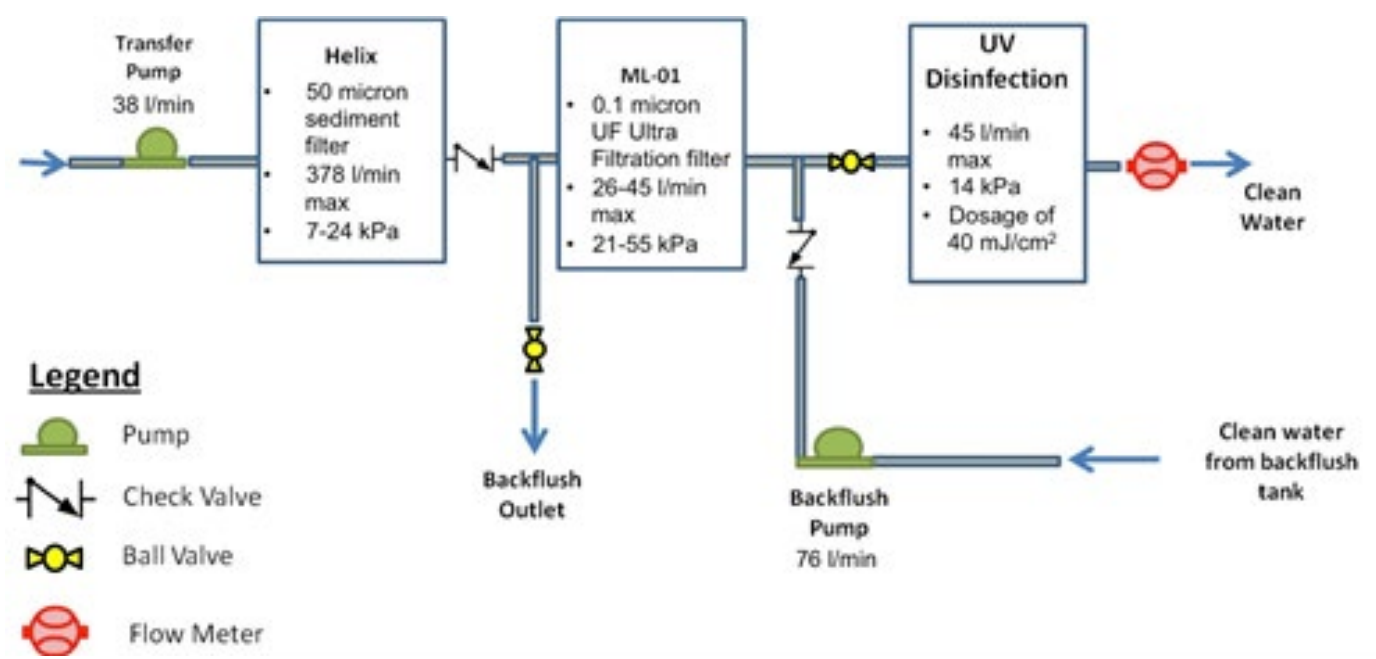

Figure 3: Purifier hydraulic flow schematic

through the flush port connection at the bottom of the filter. This minimises the maintenance required on the discs.

A 0.1 micron UF membrane filter is used as the second stage filtration. The UF membrane removes all types of bacteria and majority of viruses. The filter has a large surface of $43 \mathrm{~m} 2$ that allows for low transmembrane pressure at high flow rates. It also allows the filter to operate for long periods of time before requiring backwashing. With proper maintenance, the membrane filter has a 4 to 7 year design life (Leaman, n.d.).

To eliminate the remaining viruses that pass through the first two stages of filtration, a germicidal ultraviolet (UV) disinfection filter is used as the third stage. The UV rays deactivate the DNA of the remaining viruses and the UV bulb provides 9,000 hours $(375 \mathrm{~V})$ of consistent ultraviolet output before needing to be replaced (Viqua.com, 2014). After passing through three stages of filtration, the potable water that is distributed meets the drinking water standards set by the Environmental Protection Agency (EPA) and National Sanitation Foundation (NSF).

\subsection{Design Costs}

Table 1 summarises the cost of major mechanical components of the purifier and the site layout.

Table 1: Cost of major mechanical components

\begin{tabular}{|l|l|}
\hline Filtration component & Cost (USD) \\
\hline Purification components & $\$ 6,733.48$ \\
\hline Plumbing components & $\$ 436.60$ \\
\hline Storage tanks & $\$ 400.00$ \\
\hline Total & $\mathbf{\$ 7 , 5 7 0 . 0 8}$ \\
\hline
\end{tabular}

PURIFIER OPERATION AND MAINTENANCE

\subsection{Modes of Operation}

The system operates in two different modes: filtration mode and backwash mode. Filtration mode involves passing the well water through the mentioned stages of filtration and the purified water is stored in a clean tank.

\subsection{Sediment Filter Cleaning}

The design of the Helix HD Disc filter is such that a centrifugal action inside the filter spins away the sediment from the disc surface towards the flush port at the bottom of the filter. However, the filter discs still require to be rinsed off once a week. The filter is capable of being automatically backwashed once clogged. Implementing a backwash system for the Helix filter requires additional electrical components which complicates the overall design of the system. To retain a simplistic design, Haitian operators are trained on site to manually clean the Helix filter by flushing out the sediments trapped between the discs.

\subsection{UF Membrane Backwashing}

After being in operation for a period of time, the suspended particles in the water source form a cake layer on the membrane surface which results in a permeate flux decline or an increase in transmembrane pressure. A backwash system is utilised to lift off the cake layer and flush out the suspended particles.

During backwash mode, purified water mixed with a chlorine concentration of $1490 \mathrm{mg} / \mathrm{L}$ is passed through the UF membrane filter in reverse direction. In addition, high velocity air is blown through the filter simultaneously to increase the backwash efficiency.

The use of air sparging during backwash helps to effectively eliminate the cake layer that builds up on the membrane surface. The air improves material removal and also reduces the volume of concentrated fouling to be flushed (Serra et al., 1999).

Chlorine is added into the backwash to promote chemical breakdown of foulants (Decarolis et al., 2001). Chlorine is able to destroy organic matter that accumulates on the membrane surface and also is capable of repressing microbial growth (Nguyen, 2012). Therefore, the use 
of chlorine during backwash prevents the formation of biofilm on the membrane surface.

The overall effectiveness of backwashing to enhance membraneproductivity is directly related to the characteristics of the well water that is passed through the filter and the frequency at which backwash cycles are performed. For this reason, the system is backwashed every half-hour by the Haitian operators. A sequence of timers and time-delay relays controls the forward filtration then and backwash sequences ( $1 \mathrm{~min}$ backwash). The timer and relays implement an analog control system repairable in the field. The design includes no additional circuit boards or sensitive electronics to fail whilst in service.

\subsection{User Manual and Pictorial Guides}

After installation, a full day is allocated to train the local operators and to educate them about the functionality of the purifier (Figure 5). To further ensure understanding of operation, the team developed a quick-start pictorial guide. The quick-start guide is designed to facilitate the daily operations of the purifier. The design of the quick start

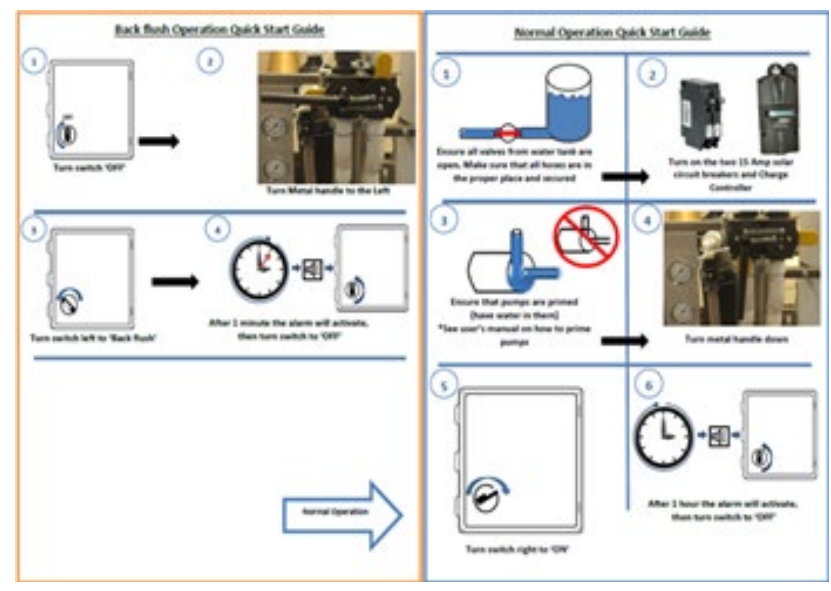

Figure 4: Pictorial based Quick-Start guide

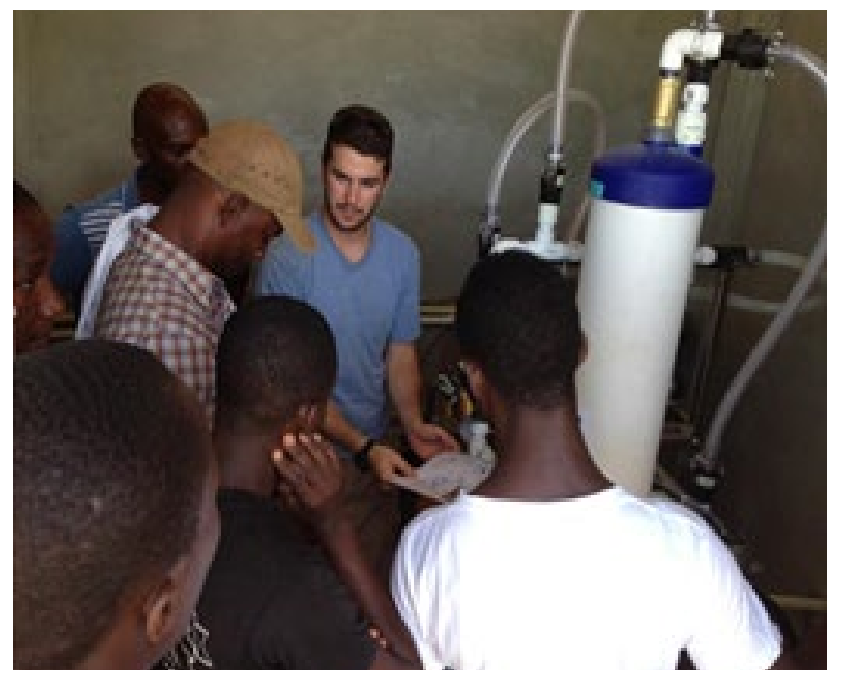

Figure 5: Haitian operators being trained with the aid of Quick-Start guide guide is illustrated in Figure 4. The operators can simply follow the diagrams laid out on the manual. In addition to the pictorial guides, a technical user manual containing computer aided drawings (CAD), schematics, datasheets and troubleshooting guides were also given to the operators of REHC. In case the system malfunctions, the user manual contains sufficient troubleshooting information.

\subsection{Annual Maintenance Costs}

The only component that requires replacement annually is the UV bulb that costs $\$ 75$ (USD). In addition, the system requires $9,200 \mathrm{~mL}$ of chlorine for chemical backwash cycles that costs approximately \$60 USD. Therefore, considering the system operates without any major malfunctions, the annual maintenance cost of the system is about \$135 USD.

\section{ELECTRICAL POWER SYSTEM}

After the earthquake, REHC paid several thousands of dollars to get city power run to the facility. However, Haiti's power grid is extremely unreliable with power available only a couple hours a day, and the cost is extremely expensive at over three dollars per kilowatt-hour (kWh). The ERAU team could not rely on this power source and decided to install two independent solar power systems for purifier operations; $1,140 \mathrm{~W}$ system for the well pump and a 1,500 W system for the pumps, air blower, and ultraviolet light on the purification system. Figure 6 illustrates the solar panel installation layout. ERAU team also assisted with the installation of a $4 \mathrm{~kW}$ solar power system for the general REHC facility. This independent power system allows REHC to have a consistent power supply for daily operations of the orphanage.

\subsection{Well Pump}

The well at REHC had been pre-dug to $40 \mathrm{~m}$ several years earlier and a hand pump had been installed on top. To provide enough water for the purification system, a solar well pump had to be installed. The team referred to the well report to ensure that the desired discharge rate would not pump the well dry. Upon arrival, the hand pump was removed and a solar well pump system was installed. The solar well pump system is a battery-less system; water pumps as long as there is solar power available. The solar well pump is a direct current (DC) pump that accepts a wide range of input voltages. This is necessary because the voltage of the solar array, which included four $285 \mathrm{~W}$ panels, varies depending on sun intensity and cloud cover.

\subsection{Purifier Solar System}

The design of a solar power system begins with determining the total solar energy required by identifying all power consuming loads, as shown in Table 2.

Table 2 sums the total energy required per day. The UV disinfection filter needs to be operating at all times. 


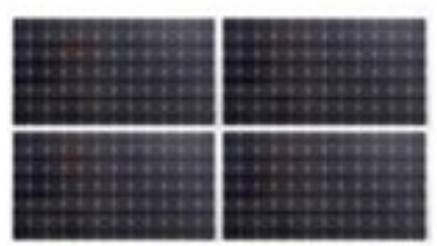

$285 W \times 4$

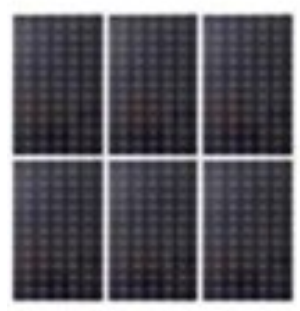

$250 \mathrm{~W} \times 6$

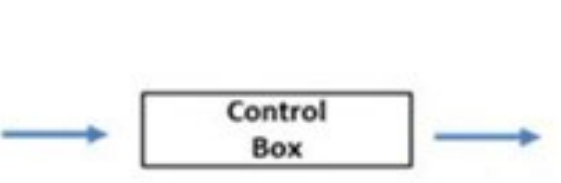

Well Pump
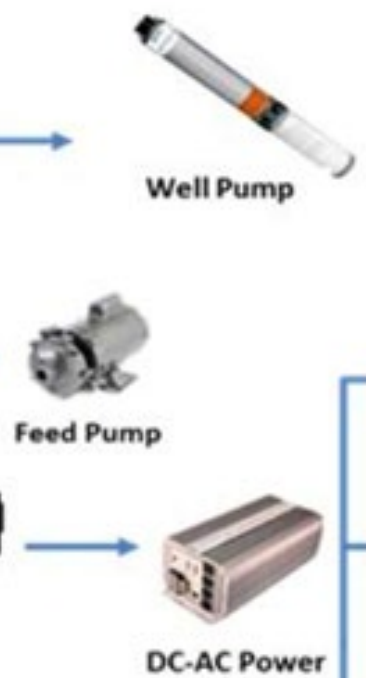

Battery Bank

\section{Charge}

Controller

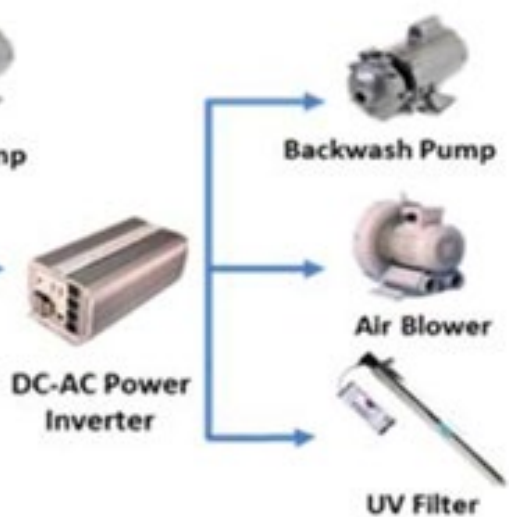

Figure 6: Solar power system for well pump and purifier loads

Table 2: REHC purifier loads

\begin{tabular}{|l|l|l|l|}
\hline Load & $\begin{array}{l}\text { Power } \\
\text { (W) }\end{array}$ & $\begin{array}{l}\text { Hours } \\
\text { needed }\end{array}$ & $\begin{array}{l}\text { Energy } \\
\text { (Wh) }\end{array}$ \\
\hline Ultraviolet filter & 43 & 48 & 2064 \\
\hline Feed pump & 373 & 8 & 2984 \\
\hline Backwash pump & 373 & 0.13 & 48.49 \\
\hline Air blower & 373 & 0.13 & 48.49 \\
\hline Totals & $\mathbf{1 , 1 6 2}$ & $\mathbf{5 6 . 2 7}$ & $\mathbf{5 , 1 4 4 . 9 8}$ \\
\hline
\end{tabular}

Therefore, as a safety precaution the design includes energy for the UV disinfection filter to operate continuously for a 48 hour period. Dividing the total energy required by 5 hours of peak sun, the theoretical power required is $1,029.5 \mathrm{~W}$. Taking into account an $80 \%$ temperature de-rating factor, the actual size of the solar panels required is $1,287 \mathrm{~W}$. The team ended up purchasing six $250 \mathrm{~W}$ panels, for a total of $1,500 \mathrm{~W}$.

The next step is to determine the battery bank size. The total storage necessary is twice the energy consumption of the system because the battery bank state of charge should not go below $50 \%$. This means that a battery bank capacity of approximately 10,000 Watt-hours (Wh) is needed. Using locally sourced deep cycle batteries, each with a voltage of $6 \mathrm{~V}$ and a capacity of $2.4 \mathrm{kWh}, 4$ batteries were required to meet the necessary capacity. Connecting these batteries in series provided 24 VDC.

Connecting the solar panels to the battery bank requires the use of a charge controller. A charge controller's main purpose is to regulate the power transfer from the solar panels to the battery and prevents battery overcharging After comparing products from multiple companies, the Midnite Classic 200 charge controller was chosen for its ability to allow higher battery charging currents over its competitors.
The purifier loads draw their power from the battery bank. However, they required alternating current (AC) power and the battery bank provided DC power. A power inverter, which converts $\mathrm{DC}$ to $\mathrm{AC}$, was required. To determine the necessary size, the total power loads needed to be summed and the startup current of the motors needed to be accounted for as well. Since the motors would not be started at the same time, the motor with the largest startup current would need to be used to spec the inverter. The backwash pump, having the largest startup current of $41 \mathrm{~A}$, equates to over $4 \mathrm{~kW}$ of power draw from the inverter during startup in addition to the roughly $1 \mathrm{~kW}$ of power from the other components. After some research, a $5 \mathrm{~kW}$ modified sine wave inverter with a $10 \mathrm{~kW}$ surge capacity from AIMS was chosen to ensure that no problems in field would occur.

\section{Electrical Power System Costs}

Table 3 summarises the cost of major electrical components of the purifier and the power system.

\section{Table 3: Cost of major electrical components}

\begin{tabular}{|l|l|}
\hline Electrical component & Cost (USD) \\
\hline Solar components & $\$ 3,850.00$ \\
\hline Purifier control box & $\$ 1,392.53$ \\
\hline Battery bank components & $\$ 2,137.68$ \\
\hline Total & $\mathbf{\$ 7 , 3 8 0 . 2 1}$ \\
\hline
\end{tabular}

\section{PURIFIER TESTING}

\subsection{Clay Dust Testing}

The system was tested at Miller-Leaman Inc., a local water purification company which provided access to their 
purifier test facilities. Miller-Leaman's engineers and technicians provided critical feedback to improve the overall design of the system. Clay test dust was used to evaluate the performance of the membrane filter during filtration mode and backwash mode. By using test dust ranging from 1 to 100 microns in size, the team was able to evaluate how the filter performs in filtration and backwash modes. Since UF filters are rated at 0.1 micron, all the clay dust was captured during filtration mode. The water sample was mixed with clay dust to create a sample with a turbidity of 10 nephalometric turbidity units (NTU). After filtering the water sample, the NTU of the backwash water and the filtered water was also measured. The filtered water turbidity was approximately $0.01 \mathrm{NTU}$. This is the expected result because low turbidity reading means the 0.1 micron membrane effectively excluded the 1 to 100 micron test dust. The backwash effluent was cloudy and obviously contained the excluded test dust.

\subsection{Baseline Pressure Testing}

The system utilises pressure gauges to measure baseline pressures for the Helix disc filter and the UF membrane filter. High turbidity water is passed through the system to purposely clog the filters until the transmembrane pressure increases. The system is then backwashed to confirm that the UF filter's transmembrane pressure drops to its baseline and the Helix disc filter is manually cleaned. The pressure across the UV disinfection filter is not measured since it is fairly low.

\subsection{Bacteria Testing}

After installing the system in Haiti, bacteria tests were performed on a well water sample and a purified water sample to ensure water safety. More than 5 colonies of bacteria are considered an abnormal amount of bacteria and water sanitation or filtration is required (Prolabinc. com, 2014). Figure 7 compares the two samples after 48 hours. The well water on the left has sufficient colonies of bacteria to cause illness. After passing through the purifier, not only does the water appear clear, it has also drastically reduced bacteria levels. The water was then determined as safe for consumption.

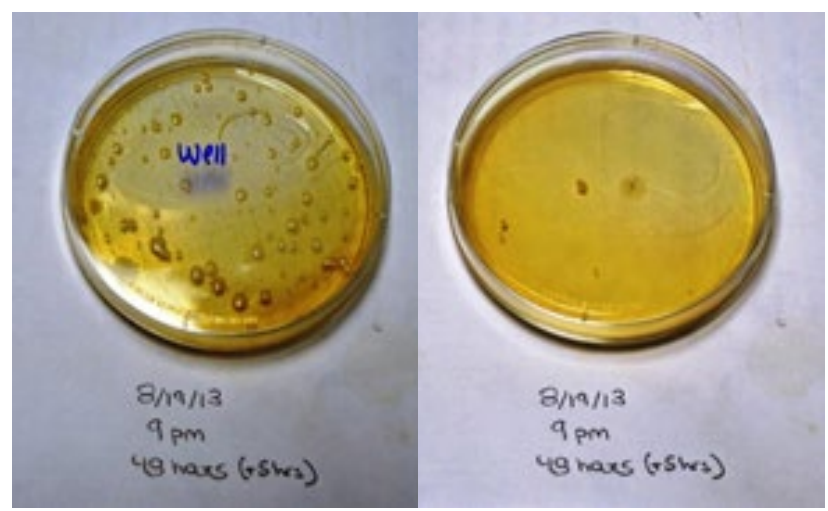

Figure 7: Bacteria tests of well water versus purified water

\section{IMPLEMENTATION}

\subsection{Installation and Partnership}

Sustainable development is essential to rebuild Haiti from the 2010 devastation. However, lack of coordination and lack of local ownership leads to unsustainable projects. Relief and development efforts require proper management to ensure the success of the project. For this reason, ERAU carefully considers each year's installation partner before committing to the partnership. Each partner is evaluated under the following criteria:

- A US-based organisation exists to provide ongoing communication, support, and maintenance.

- Representatives in Haiti are available and willing to cooperate and assist pre-trip planning and on-site installation.

- Partner has a sufficient budget prepare for on-site installation prior to our arrival.

- A well is available with a stable bore hole located in a secure area.

- Partner has compatible goals and visions.

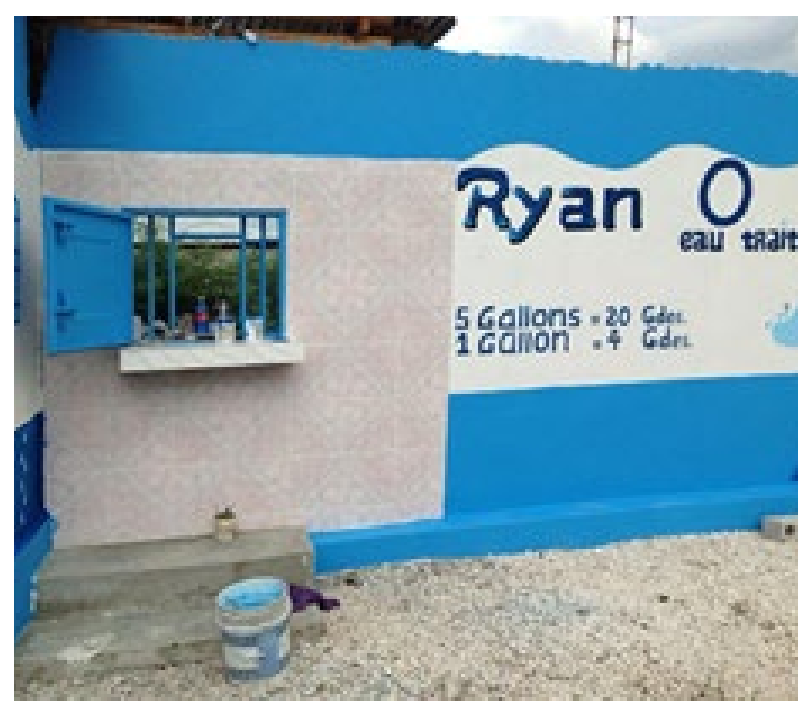

Figure 8: Water-selling micro-business storefront

\subsection{Micro-Business Development}

The excess water is sold to the surrounding communities through a micro-business. REHC set up a water-selling store front as illustrated in Figure 8.

Such storefronts are very common in Haitian communities; however when the team collected water samples from competing stores nearby, the water sold in certain stores were not of drinking water quality. To encourage the local community to purchase water from a reliable source, REHC sells the water at a cheaper price in comparison to other local water stores nearby. The generated income facilitates the maintenance costs of the purification system. The micro-business has also created multiple jobs in the area. 

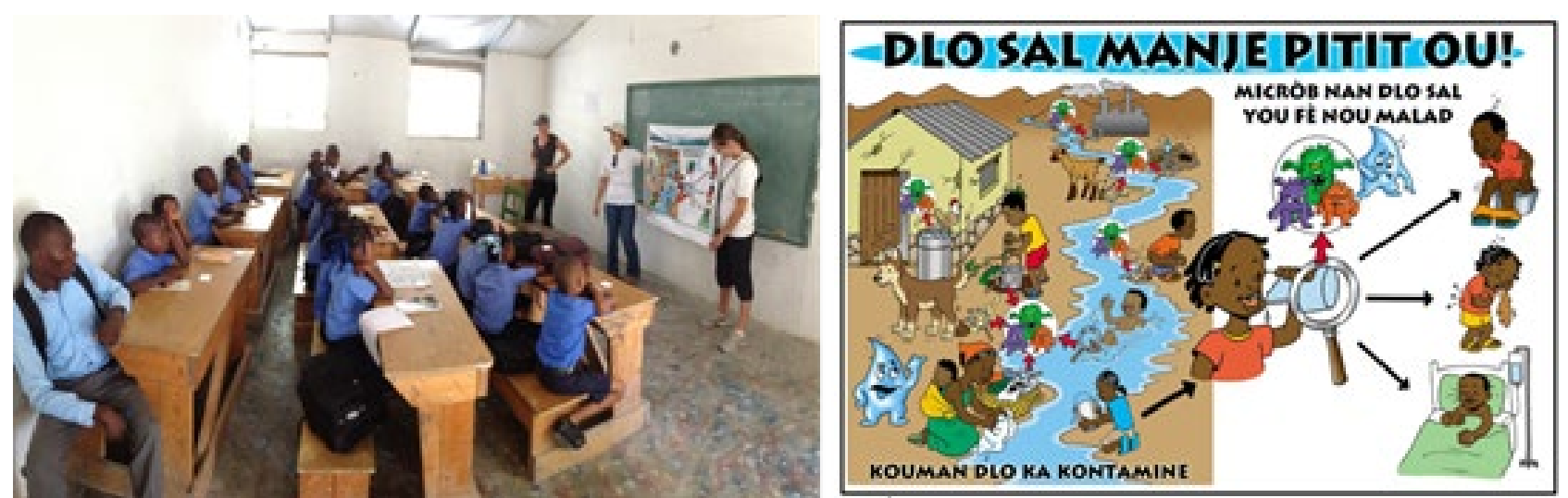

Figure 9: Water Sanitation and Hygiene training with the aid of pictorial posters

\section{WATER, SANITATION AND HYGIENE TRAINING}

Poor sanitation, unsafe water and unhygienic practices are a major cause for disease in developing nations. Despite being preventable, water and hygiene related disease remains one of the most significant child health problems around the world. Diarrhea alone kills over 3,000 children each day and $88 \%$ of diarrheal disease is related to unsafe drinking water, inadequate sanitation and poor hygiene (UNICEF, 2014). As illustrated in Figure 9, ERAU utilises pictorial hygiene posters that are written in Haitian Creole to educate the local community and children at REHC. Through WASH training, ERAU aims to promote the value of the purification system as well as to attract the local community to purchase the clean water from the REHC micro- business.

\subsection{Future Design Improvements}

As of this writing, ERAU has installed three communityscale purifiers at various Haitian communities. The main design setback the team has experienced so far has been the cost associated with shipping the unit over to Haiti. Current design contains an assembly that includes a bulky stainless frame, large filters and heavy pumps. Due to the large size and weight of the current design, shipping is a major cost factor. ERAU is currently working on a more modular design for the purifier instead of a single large assembly. Since a team of about 12 members travel to Haiti for the installation of the unit, the idea is to have a design such that a majority of the components of the purifier could be checked in as airline oversized luggage whilst travelling.

\section{CONCLUSIONS}

The Project Haiti 2013 team designed and installed a 38 $\mathrm{L} / \mathrm{min}$ water purifier with an $1100 \mathrm{~W}$ submersible well pump. The backwash capability of the system allows the main filtration component to be cleaned in place and leads to a design life of 4 to 7 years. The system consists of a simplistic design with very few custom components. Since the majority of the components used in the system are off-the-shelf, it allows the end user easy access to re- place any components in case of failure. By collaborating with an installation partner with a US-based organisation, ERAU engineers are able to assist in case the system malfunctions due to ongoing communications. Two 3,700 $\mathrm{L}$ tanks store well-water for the use of general orphanage operations. One 3,700 L tank stores the purified water and is used by the 200 children and staff at the orphanage. The excess water is sold to the local community through a store front located at REHC. The installation of the purification system has also helped to create local jobs in the area. ERAU receives frequent updates from REHC staff regarding the purifier. Since installed in May 2013, the system is currently in operation without any major malfunctions. ERAU intends to continue doing similar work in Haiti to provide clean drinking water to those in need.

\section{REFERENCES}

Decarolis, J, Hong, S., \& Taylor, J., 2001, 'Fouling behavior of a pilot scale inside-out hollow fiber UF membrane during dead-end filtration of tertiary wastewater'. Journal of Membrane Science, vol. 191, no.1, pg.165-178, doi: 10.1016/S0376-7388(01)00455-0

Leaman, M., n.d., Helix HD Series Owner's Manual, 1st ed., viewed 11 August 2014, <http://www.millerleaman. com/files/products/brochures/helixhdsalessheet1.pdf>

Leaman, M., n.d., Ultra-Pure UF Membrane User's Manual, 1st ed., viewed 11 August 2014, <http://www. millerleaman.com/files/products/brochures/ufmembrane cutsheet2009.pdf>

Lies, A., 2011, The earthquake in Haiti, 1st ed., ABDO Publishing Company: Edina, MN, USA, pp.12-13.

Nguyen, T., Roddick, F. \& Fan, L., 2012, 'Biofouling of water treatment membranes: a review of the underlying causes, monitoring techniques and controlmeasures', Membranes, vol. 2 no. 4, pp. 804-840, doi: 10.3390/ membranes 2040804

Prolabinc.com, 2014, Bacteria Test Kit - Instructions, viewed 12 August 2014, <http://www.prolabinc.com/instructions/bacteria.html $>$ 
Serra, C., Durand-Bourlier, L., Clifton, M., Moulin, P., Rouch, J. \& Aptel, P., 1999, 'Use of air sparging to improve backwash efficiency in hollow-fiber modules', Journal of Membrane Science, vol. 161, no. 1, pp. 95-113, doi: 10.1016/S0376-7388(99)00106-4

Tang, Y., Compere, M., Wong, Y., Coleman, J. \& Selkirk, M., 2012, 'High Tech High Touch: Lessons Learned from Project Haiti 2011', American Society for Engineering Education (ASEE) Annual Conference and Exposition Proceedings, 10-13 June 2012, San Antonio, TX, USA.

Viqua.com, 2014, SCM-320 Product Information, viewed 12 August 2014, <http://dealer.viqua.com/product. php? $\mathrm{p}=112 \& \mathrm{l}=1>$
Wong, Y., Camp, J., Pinto, S., Fennesy, K., Compere, M. \& Tang, Y., 2014, 'Project Haiti 2012: providing an experiential learning experience through the design and delivery of a water purifier in Haiti', American Society for Engineering Education (ASEE) South Eastern Section Conference, Tennessee Technological University, Cookeville, TN, USA.

UNICEF, 2014, Links to health, education and development, viewed 12 August 2014, <http://www.unicef. org/wash/index healthandeducation.html> 